\title{
Influence of Seasonality on Phytochemical Composition, Phenolic Content and Antioxidant Activity of Neoglaziovia variegata (Bromeliaceae)
}

\author{
Mayara Amariz Gomes ${ }^{1}$ (D), Bárbara Elizabeth Alves de Magalhães ${ }^{2}$ (iD), \\ Walter Nei Lopes dos Santos 2,3 (D), Jackson Roberto Guedes da Silva Almeida 1,*(i) \\ 1 Núcleo de Estudos e Pesquisas de Plantas Medicinais, Universidade Federal do Vale do São Francisco, 56304-205, \\ Petrolina, Pernambuco, Brazil; mayara_amariz@ @otmail.com (M.A.G.); \\ 2 Instituto de Química, Universidade Federal da Bahia, 40170-290, Salvador, Bahia, Brazil; barbara.elisabeth@ hotmail.com \\ (B.E.A.M.); \\ 3 Departamento de Ciências Exatas e da Terra, Universidade do Estado da Bahia, 41195-001 Salvador, Bahia, Brazil; \\ waltrs8@gmail.com (W.N.L.S.); \\ * Correspondence: jackson.guedes@univasf.edu.br (J.R.G.S.A);
}

Received: 18.05.2021; Revised: 28.06.2021; Accepted: 5.07.2021; Published: 8.08.2021

\begin{abstract}
The production of phytochemicals in plants can be influenced by several factors. This work evaluated the influence of seasonality on phytochemical composition, phenolic content, and antioxidant activity of Neoglaziovia variegata. The leaves were harvested for a year. Phytochemical characterization by thin-layer chromatography indicated the presence of anthocyanins, anthraquinones, anthracene derivatives, flavonoids, tannins, monoterpenes, diterpenes, triterpenes, and steroids in the leaves collected in all months, and coumarins in leaves of 4 of the 12 months of collection. The antioxidant activity, evaluated in vitro, ranged from 33.0 to $86.1 \%$ inhibition of $\mathrm{DPPH}^{\circ}$ and from 36.2 to $97.8 \%$ inhibition of $\mathrm{ABTS}^{\circ+}$. The total phenolic content, determined using Folin-Ciocalteu reagent, varied between 21.5 and $65.8 \mathrm{mg}$ GAE/g. Phenolic acids and flavonoids were determined by HPLCDAD, with higher concentrations of kaempferol (0.47-3.57 mg/g), p-coumaric $(0.19-3.59 \mathrm{mg} / \mathrm{g})$ and ellagic (0.26-3.31 mg/g) acids. The Principal Component Analysis (PCA) indicated the separation of the leaf samples according to the season. It was demonstrated the influence of seasonality on the antioxidant activity and phytochemical composition of $N$. variegata leaves and that this species is rich in secondary metabolites of different classes, with potential applications in several areas, such as pharmaceutical and food.
\end{abstract}

Keywords: Neoglaziovia variegata; Bromeliaceae; antioxidant activity; phytochemicals; phenolic compounds; seasonality; HPLC-DAD; PCA.

(C) 2021 by the authors. This article is an open-access article distributed under the terms and conditions of the Creative Commons Attribution (CC BY) license (https://creativecommons.org/licenses/by/4.0/).

\section{Introduction}

The Bromeliaceae family is composed of 56 genera and more than 3000 species [1]. It is one of the morphologically and ecologically most diverse plant families. Bromeliads vary from terrestrial to epiphytical, found from sea level to altitudes above $4,000 \mathrm{~m}$, in places with very high or low luminosity, in humid and desert regions, in soils subject to floods and rocky, capable of withstanding very high or low temperatures, near to $0{ }^{\circ} \mathrm{C}$. Bromeliads are acknowledged mainly for their ornamental value, but some species in the Bromeliaceae family are grown for fruit production, and some species have proven medicinal properties [2]. 
Neoglaziovia variegata is a bush belonging to the Bromeliaceae family that grows spontaneously in the semi-arid region of northeastern Brazil [3]. Popularly known as "caroá", "craua" or "macambira de corda", N. variegata grows in non-compact rocky soils and is often found in the Caatinga, except in its most humid areas. This species produces soft, flexible, and high-quality fibers extracted from its leaves and processed for the production of craftwork, ropes, baskets, hats, and rugs. Fibers have also been used as a raw material in small textile industries. The Neoglaziovia variegata fruit is known in popular medicine, being used the tea to treat cough, bronchitis, flu, and pneumonia [4]. Previous studies report that the ethanolic extract from the leaves of $N$. variegata presents gastroprotective effects in a mice model of gastric ulcer [5] and antinociceptive [6]. It was also observed that extracts and fractions from the leaves of Neoglaziovia variegata have antioxidant, antibacterial, and photoprotective properties [7, 8, 9]. Studies have also indicated potential analgesic activity of $N$. variegata [4]. The chemical composition of the species is still poorly investigated. In a recent study by Juvik et al. [10], non-polar natural products of Neoglaziovia variegata were identified, including fatty acids (9Z)-octadec-9-enoic acid (oleic acid), $n$-hexadecanoic acid (palmitic acid), and octadecanoic acid (stearic acid), plant sterols such as campesterol, $\beta$-sitosterol, ergostanol, stigmasta-4,22-dien-3- $\beta$-ol, the very-long-chain (VLC) alkanes $n$-nonacosane and $n$ triacontane and the vitamins $\alpha$ - and $\beta$-tocopherol. Furthermore, Fossen et al. [11] reported the first identification of a poly-oxygenated flavone glucoside from $N$. variegata, novel flavone aglycone, 5,6,7,4'-tetrahydroxy-3',5'-dimethoxy-flavone, and quercetin-3-O-(6"-O- $\alpha$ rhamnopyranosyl- $\beta$-D-glucopyranoside) (rutin), both with MOLM-13 antileukemic activity.

This work aimed to evaluate the influence of seasonality on phytochemical composition, phenolic content, and antioxidant activity of ethanol extracts obtained from Neoglaziovia variegata leaves harvested in different seasons for 12 consecutive months. Phytochemical characterization was performed by thin-layer chromatography, being evaluated the main classes of secondary metabolites. The antioxidant activity of the extracts was evaluated in vitro through free radical capture assay $\left(\mathrm{DPPH}^{\cdot}\right.$ and $\left.\mathrm{ABTS}^{\cdot+}\right)$. The total phenolic content (TPC) was determined by spectrophotometry, and by HPLC-DAD, the phenolic compounds (phenolic acids and flavonoids) were identified and quantified individually. To discuss the influence of seasonality, the Tukey test was applied to the results of spectrophotometric determinations (TPC, DPPH, and ABTS), and Principal Component Analysis (PCA) was applied to the data of the analysis of phenolic compounds by HPLC-DAD.

\section{Materials and Methods}

\subsection{Chemicals and reagents.}

Gallic, protocatechuic, vanillic, chlorogenic, caffeic, syringic, p-coumaric, ferulic, ellagic and trans-cinnamic acids, quercetin, (+)-catechin, rutin, kaempferol, naringenin, chrysin, 2,2-diphenyl-1-picrylhidrazyl (DPPH), 2,2'-azinobis (3-ethylbenzthiazoline-6sulphonic acid) (ABTS) and anisaldehyde were purchased from Sigma-Aldrich (St. Louis, USA). Potassium hydroxide, potassium persulfate, methanol, ethanol, chloroform, diethylamine, ethyl acetate, ethyl ether, petroleum ether, formic acid, acetic acid, hydrochloric acid, sulfuric acid, and toluene from Synth (São Paulo, Brazil). Methanol HPLC grade and vanillin from Merck (Darmstadt, Germany). Glacial acetic acid HPLC grade from J.T.Baker (Phillipsburg, USA). Sodium carbonate, potassium iodide, and iodine from Vetec (Brazil). Ultrapure water from the Master P\&D purification system (Gehaka, São Paulo, Brazil) was 
used to prepare the HPLC mobile phase. The other experiments used ultrasound water from the Milli-Q system (Millipore, Bedford, USA).

\subsection{Plant material.}

The leaves of Neoglaziovia variegata Mez (Bromeliaceae) were collected in the city of Petrolina (coordinates: S 9 $19^{\prime} 52.10^{\prime \prime}$, W 40³2'47.40”, altitude $381 \mathrm{~m}$ ), State of Pernambuco, Northeast Brazil, in the Caatinga area. The harvest was carried out between July 2017 and June 2018 (Southern Hemisphere seasons). The material was collected from healthy specimens with similar characteristics and the same environmental conditions in each case. The botanical identification was made by comparing the collected sample with a voucher of the species deposited at the Herbário Vale do São Francisco (HVASF) of the Universidade Federal do Vale do São Francisco (UNIVASF), with number 18309. The samples were coded according to the month of leaf collection: Jul (July/2017), Aug (August/2017), Sep (September/2017), Oct (October/2017), Nov (November/2017), Dec (December/2017), Jan (January/2018), Feb (February/2018), Mar (March/2018), Apr (April/2018), May (May/2018), and Jun (June/2018). All procedures for access to genetic patrimony and associated traditional knowledge were carried out, and the project was registered in SisGen (Register \#A3CF66C).

\subsection{Extraction.}

The dried and powdered leaves of $N$. variegata were subjected to maceration at room temperature $\left(25{ }^{\circ} \mathrm{C}\right)$ using $95 \%$ ethanol as solvent [7]. Four extractions were performed, renewing the solvent every $72 \mathrm{~h}$ until the drug was completely depleted. Then, the extractive solution was filtered and concentrated on a rotary evaporator under reduced pressure at an average temperature of $50^{\circ} \mathrm{C}$. The dried extracts were solubilized in methanol $(10 \mathrm{mg} / \mathrm{mL})$ and stored at $-20^{\circ} \mathrm{C}$.

\subsection{Phytochemical analysis.}

The main secondary metabolites were evaluated by thin-layer chromatography (TLC). Approximately $10 \mu \mathrm{L}$ of the extract solutions were applied in plates of silica gel $60 \mathrm{~F}_{254}$ in aluminum supports (Merck, Darmstadt, Germany), eluted in different solvent systems, and applied in specific revelators for each secondary metabolite class [12,13] (Table 1). The plates were visualized in a UV camera (CE-850, CIENLAB, Brazil) at 254 and $365 \mathrm{~nm}$. The evaluation of the phytochemical presence in the extracts was based on the spots profile and comparison with reference standards.

Table 1. Elution systems and revelators used to characterize the main secondary metabolites by TLC.

\begin{tabular}{l|l|l} 
Phytochemicals & Elution systems (v/v) & Revelators \\
\hline Alkaloids & Toluene: ethyl acetate: diethylamine (70:20:10) & Dragendorff reagent \\
\hline Anthocyanins & Ethyl acetate: formic acid: acetic acid: water (100:11:11:26) & Sulfuric anisaldehyde \\
\hline Anthracene derivatives & Ethyl acetate: methanol: water (100:13,5:10) & $10 \%$ ethanolic KOH \\
\hline Anthraquinones & Petroleum ether: ethyl acetate: formic acid (75:25:1) & Phosphomolybdic acid \\
\hline Coumarins & Toluene: ethyl ether (1:1, saturated with acetic acid 10\%) & $10 \%$ ethanolic KOH \\
\hline Flavonoids and tannins & Ethyl acetate: formic acid: glacial acetic acid: water (100:11:11:26) & NEU reagent \\
\hline Lignans & Chloroform: methanol: water (70:30:4) & Vanillin phosphoric \\
\hline Mono and diterpenes & Toluene: ethyl acetate (93:7) & Vanillin sulphuric \\
\hline Naphthoquinones & Toluene: formic acid (99:1) & $10 \%$ ethanolic KOH \\
\hline Saponins & Chloroform: glacial acetic acid: methanol: water (64:32:12:8) & Sulfuric anisaldehyde \\
\hline Triterpenes and steroids & Toluene: chloroform: ethanol (40:40:10) & Liebermann-Burchard \\
\hline Xanthines & Ethyl acetate: methanol: water (100:13,5:10) & Iodine-KI-HCl
\end{tabular}




\subsection{Total Phenolic Content (TPC).}

The TPC determination was performed with the Folin-Ciocalteu reagent by the colorimetric method described by Oliveira-Júnior et al. [8]. For each extract, in triplicate, an aliquot of $40 \mu \mathrm{L}$ was added to $3.16 \mathrm{~mL}$ of ultrapure water and $200 \mu \mathrm{L}$ of Folin-Ciocalteu reagent and then agitated. $600 \mu \mathrm{L}$ of sodium carbonate aqueous solution $(20 \% \mathrm{w} / \mathrm{v})$ was added after 6 minutes, and the solutions were left to rest at $25^{\circ} \mathrm{C}$ for $2 \mathrm{~h}$. The absorbance of each solution was determined at $765 \mathrm{~nm}$, and the total phenolic content of the extracts was measured with a gallic acid calibration curve $(0,5-10 \mathrm{mg} / \mathrm{L} ; \mathrm{y}=0,1251 \mathrm{x}+0,0901 ; \mathrm{R}=0,9927)$ and expressed as milligram of gallic acid equivalent per gram of dried extract (mg GAE/g).

\subsection{In vitro antioxidant activity.}

\subsection{1. $\mathrm{DPPH}^{\bullet}$ radical scavenging activity.}

For each extract, in triplicate, an aliquot of $100 \mu \mathrm{L}$ was added to $3.9 \mathrm{~mL}$ of $\mathrm{DPPH}^{\bullet}$ methanolic solution $(0,06 \mathrm{mM})$, prepared before the analysis. Finally, the solutions were stirred and kept at rest in a dark environment at room temperature $\left(25^{\circ} \mathrm{C}\right)$ for $60 \mathrm{~min}$. The absorbances were measured at $515 \mathrm{~nm}$ in a UV-Vis spectrophotometer (Quimis, Diadema, Brazil), and the antioxidant capacity was expressed as a percentage of inhibition: $\%$ inhibition $=100 \mathrm{x}$ (ABS blank - ABS sample)/(ABS blank) [14].

\subsection{2. $\mathrm{ABTS}^{\cdot+}$ radical scavenging activity.}

The $\mathrm{ABTS}^{\cdot+}$ solution was prepared by adding $5 \mathrm{~mL}$ of ABTS aqueous solution $(7 \mathrm{mM})$ and $88 \mu \mathrm{L}$ of potassium persulfate aqueous solution $(140 \mathrm{mM})$, then the solution was stirred and kept at rest in a dark environment at room temperature $\left(25^{\circ} \mathrm{C}\right)$ for 16 hours. $1 \mathrm{~mL}$ of the $\mathrm{ABTS}^{\cdot+}$ solution was diluted with ethanol to the absorbance of $0.70 \pm 0.05$ at $734 \mathrm{~nm}$. In triplicate, $30 \mu \mathrm{L}$ of each extract was added to $3 \mathrm{~mL}$ of the $\mathrm{ABTS}^{{ }^{+}}$diluted solution and stirred. The absorbances were measured at $734 \mathrm{~nm}$ after $6 \mathrm{~min}$ in a UV-Vis spectrophotometer (Quimis, Diadema, Brazil), and the antioxidant activity was expressed as a percentage of inhibition [14].

\subsection{HPLC-DAD analyses.}

HPLC-DAD analyses were performed on a liquid chromatography Prominence model (Shimadzu Scientific Instruments, Kyoto, Japan), equipped with diode array detector (SPD20A model), quaternary pump (LC-20AD model), heating furnace (CTO-20A model), and automatic sampler (SIL-20A model), and controlled by LCsolutions software. Chromatographic separation was performed on a Lichrospher RP 18 column $(5 \mu \mathrm{m}, 4.6 \times 250$ $\mathrm{mm}$ ) (Agilent, Waldbronn, Germany), at $40{ }^{\circ} \mathrm{C}$ and flow rate $1.0 \mathrm{~mL} / \mathrm{min}$ of (A) ultrapure water acidified with glacial acetic acid $1 \%(\mathrm{v} / \mathrm{v})$ and $(\mathrm{B})$ methanol according to the gradient program: 0-10 min, $100 \% \mathrm{~A} ; 10-20 \mathrm{~min}, 30 \% \mathrm{~A}$ and $70 \% \mathrm{~B} ; 20-21,25 \% \mathrm{~A}$ and $75 \% \mathrm{~B} ; 21-25,100 \% \mathrm{~A}$ [15]. Before the injection $(20 \mu \mathrm{L})$ in the HPLC-DAD system, the extract solutions were filtered through a PTFE $(0.45 \mu \mathrm{m})$ syringe filter.

The analyte identification was based on the retention times and UV spectra compared to the reference standards. Chromatograms were obtained at different wavelengths: 260 for protocatechuic, ellagic, and vanillic acids; 272 for syringic acid and chrysin; 280 for transcinnamic, gallic and ferulic acids, catechin, and naringenin; 310 for $p$-coumaric acid; 330 for chlorogenic and caffeic acids; 360 for rutin, quercetin, and kaempferol. 
The identified analytes were quantified using the external calibration curves $(0.1-2.5$ $\mathrm{mg} / \mathrm{L})$ of protocatechuic acid $(\mathrm{y}=122913 \mathrm{x}+453, \mathrm{R}=0.9950)$, ellagic acid $(\mathrm{y}=17803 \mathrm{x}-2863$, 0.9940), syringic acid ( $\mathrm{y}=66621 \mathrm{x}-1175, \mathrm{R}=0.9997)$, transcinnamic acid $(\mathrm{y}=149100 \mathrm{x}-634$, $\mathrm{R}=0.9997)$, gallic acid $(\mathrm{y}=54239 \mathrm{x}-22464, \mathrm{R}=0.9968)$, ferulic acid $(\mathrm{y}=54238 \mathrm{x}-1845, \mathrm{R}$ $=0.9998), p$-coumaric acid $(\mathrm{y}=162544 \mathrm{x}-813, \mathrm{R}=0.9997)$, chlorogenic acid $(\mathrm{y}=54804 \mathrm{x}-$ $809, \mathrm{R}=0.9996)$, caffeic acid $(\mathrm{y}=106892 \mathrm{x}-655, \mathrm{R}=0.9997)$, catechin $(\mathrm{y}=12726 \mathrm{x}-418, \mathrm{R}$ $=0.9995)$, rutin $(\mathrm{y}=160367 \mathrm{x}-68337, \mathrm{R}=0.9919)$, quercetin $(\mathrm{y}=36322 \mathrm{x}-3352, \mathrm{R}=0.9983)$, and kaempferol $(\mathrm{y}=32537 \mathrm{x}-1657, \mathrm{R}=0.9986)$. The results were expressed as milligram per gram of dried extract $(\mathrm{mg} / \mathrm{g})$.

\subsection{Statistical analyses.}

Tukey's multiple comparison test was applied to analyze the influence of seasonality on the total phenolic content and antioxidant activity of $N$. variegata leaf extracts, evaluating if there was a significant difference for these factors during one year. The Tukey test was applied using a completely randomized domain for the 95\% confidence level in MS Excel for Windows.

Principal Components Analysis (PCA) was applied for the comparative analysis of the phenolic composition of $N$. variegata leaf extracts to identify how seasonality influenced the production of phenolic acids and flavonoids during one year. The multivariate analysis was based on the triplicate means. PCA was performed with the data standardized centered on the average in the STATISTICA 7.0 software (Stat-Soft Inc., USA).

\section{Results and Discussion}

\subsection{Phytochemical analysis.}

Secondary metabolites do not play a crucial role in the normal growth, development, and reproduction of plants, but they do act in the plant's defense system, in interspecies protection and protecting damage to the ecological environment. Each plant's family, genus, and species produces a characteristic mixture of secondary metabolites, which are extremely diverse and divided into several classes [16].

The results of the phytochemical analysis are shown in Table 2. Qualitative analysis indicated the absence of alkaloids, lignans, naphthoquinones, saponins, and xanthines in all extracts of $N$. variegata leaves. Oliveira-Júnior et al. [8] also reported that the ethanolic extract of $N$. variegata leaves was negative for the presence of alkaloids, lignans, and naphthoquinones, as well as for coumarins, while in the present study, the absence of coumarins was also observed in some months (August, October, and January to June), but its presence was verified in the other months (July, September, November, and December).

Table 2. Phytochemical characterization of extracts of Neoglaziovia variegata leaves collected in different seasons.

\begin{tabular}{l|c|c|c|c|c|c|c|c|c|c|c|c} 
Phytochemicals & Jul & Aug & Sep & Oct & Nov & Dec & Jan & Feb & Mar & Apr & May & Jun \\
\hline Alkaloids & - & - & - & - & - & - & - & - & - & - & - & - \\
\hline Anthocyanins & ++ & ++ & ++ & ++ & ++ & ++ & ++ & + & + & ++ & ++ & ++ \\
\hline $\begin{array}{l}\text { Anthracene } \\
\text { derivatives }\end{array}$ & ++ & ++ & ++ & ++ & ++ & ++ & ++ & ++ & ++ & ++ & ++ & ++ \\
\hline Anthraquinones & ++ & ++ & ++ & ++ & ++ & ++ & ++ & ++ & ++ & ++ & ++ & ++ \\
\hline Diterpenes & +++ & +++ & ++ & +++ & ++ & +++ & ++ & +++ & ++ & +++ & +++ & +++ \\
\hline Coumarins & + & - & + & - & + & + & - & - & - & - & - & - \\
\hline $\begin{array}{l}\text { Flavonoids } \\
\text { https://biointerfaceresearch.com/ }\end{array}$ & ++ & ++ & ++ & ++ & ++ & ++ & +++ & +++ & +++ & +++ & ++ \\
\hline
\end{tabular}




\begin{tabular}{l|c|c|c|c|c|c|c|c|c|c|c|c}
\hline Phytochemicals & Jul & Aug & Sep & Oct & Nov & Dec & Jan & Feb & Mar & Apr & May & Jun \\
\hline Lignans & - & - & - & - & - & - & - & - & - & - & - & - \\
\hline Monoterpenes & +++ & +++ & ++ & +++ & ++ & +++ & ++ & +++ & ++ & +++ & +++ & +++ \\
\hline Naphthoquinones & - & - & - & - & - & - & - & - & - & - & - & - \\
\hline Saponins & - & - & - & - & - & - & - & - & - & - & - & - \\
\hline Steroids & + & + & ++ & + & ++ & + & + & + & + & + & + & + \\
\hline Tannins & ++ & + & ++ & ++ & ++ & ++ & ++ & +++ & +++ & +++ & +++ & ++ \\
\hline Triterpenes & + & + & ++ & + & ++ & + & + & + & + & + & + & + \\
\hline Xanthines & - & - & - & - & - & - & - & - & - & - & - & -
\end{tabular}

-: not detected; +: weak presence; ++: moderate presence; +++: strong presence.

The phytochemical composition of the plant is influenced by several biotic and abiotic factors, which affect the production, quantity, and nature of the biosynthesized compounds by the plant [17]. In an adaptive process in response to external changes, qualitative and quantitative changes occur in the phytochemical composition of the plant, which may result in the accumulation or absence of metabolites in different seasons [18].

All extracts showed positive reactions for the presence of anthocyanins, anthraquinones, anthracene derivatives, flavonoids, tannins, terpenes (mono-, di-, tri-), and steroids. The presence of anthracene derivatives, flavonoids, tannins, terpenes, and steroids in ethanolic extract of $N$. variegata leaves has been reported previously [8]. Only for anthraquinones, the same response intensity was observed for all months, while for the other classes of secondary metabolites, there was variation in the response intensity for extracts of leaves collected in different months, which reflects the variation in the concentration of these compounds on N. variegata leaves during the year.

Plants biosynthesize secondary metabolites according to their particular needs [16], and the production is influenced by several factors, such as seasonality, temperature, ultraviolet radiation, atmospheric composition, water availability, and attacks by pathogens and insects [19], which may explain differences in the phytochemical composition of the plant throughout the year, as noted in the extracts of $N$. variegata leaves.

Plants have several secondary metabolites with interesting pharmacological activities, which can be isolated for drug development. Due to their diverse functional properties, phytochemicals also have medical, biological, chemical, and agricultural applications [16]. Phytochemical analysis revealed that Neoglaziovia variegata leaves have a wide variety of secondary metabolites from different classes, with several potential applications in different areas, such as pharmaceutical, cosmetic, food, medical, agricultural and biochemical.

Flavonoids are one of the most important groups of phenolic compounds and act in various functions in plants, such as in defense against insects, fungi, viruses, and bacteria and protection against ultraviolet radiation [20]. Biochemical activities depend mainly on the chemical structures of flavonoids [21]. Antioxidant, anti-inflammatory, and anti-cancer activities are reported and the prevention of neurodegenerative diseases attributed to flavonoids. Anthocyanins are conjugated sugar derivatives of anthocyanidins (group of flavonoids), with the main function of protection against damage from excessive sunlight [22].

Tannins are a group of phenolic compounds that exhibit various pharmacological activities. They have the capacity to control insects, fungi, and bacteria [20], have antiinflammatory activity and astringents, and diuretic properties. Plants that contain tannins are used against diarrhea and stomach and duodenal tumors [16]. Coumarins have antifungal activity and have pharmacological, biochemical, and therapeutic applications, depending on specific substitution patterns [20]. 
Quinones have several biological activities, such as antioxidant, antibacterial, and antitumor. Anthraquinones exhibit antifungal [23], antimicrobial, anti-inflammatory [24] and laxative activities [25]. Plants that contain anthracene derivative compounds, such as anthraquinones, have been used for millennia in the treatment of constipation and have been reported to act as anti-cancer [26].

Terpenoids have several biological properties, such as antioxidant and antimicrobial activities [20]. In plants, they act in the defense system, wound scaling, and thermotolerance. Some diterpenes have anti-hypertensive and anti-cancer activities. Monoterpenes exhibit analgesic and anti-inflammatory activities [25], and derivatives of monoterpenes are used in commercial insecticides. Triterpenes are components of several important bioactive compounds, such as steroids, saponins, cardioactive glycosides, corticosteroids, and mammalian sex hormones [22]. Among plant terpenes, the most abundant are triterpenoids, which exhibit anti-inflammatory activity and hemolytic properties [25].

\subsection{Spectrophotometric determinations.}

The results of the spectrophotometric determinations (total phenolic content and in vitro antioxidant activity) are shown in Table 3. The TPC varied between $21.5 \pm 1.6$ and $65.8 \pm 1.0$ mg GAE/g, with a significant difference (according to the Tukey test) in the total phenolic content in the $N$. variegata leaves collected in different months during one year. The lowest concentration of phenolic compounds was obtained in the extract of leaves collected in December (2017). The highest concentration of phenolics was found in the extract of the leaves collected in July (2017). In a previous study with $N$. variegata, a higher concentration of total phenolic compounds in the ethanolic extract of the leaves was reported: TPC $=84.33 \pm 3.82$ $\mathrm{mg} \mathrm{GAE} / \mathrm{g}$ [8].

Table 3. Total phenolic content (TPC) and antioxidant activities of extracts of Neoglaziovia variegata leave collected in different seasons.

\begin{tabular}{l|c|c|c} 
Sample & TPC $(\mathbf{m g}$ GAE $/ \mathbf{g})$ & DPPH $(\%$ inhibition $)$ & ABTS (\% inhibition) \\
\hline Jul & $65.8^{\mathrm{a}} \pm 1.0$ & $84.1^{\mathrm{ab}} \pm 0.2$ & $96.9^{\mathrm{a}} \pm 0.5$ \\
\hline Aug & $45.6^{\mathrm{cd}} \pm 1.9$ & $86.1^{\mathrm{a}} \pm 0.2$ & $57.3^{\mathrm{cd}} \pm 2.3$ \\
\hline Sep & $38.5^{\mathrm{de}} \pm 1.2$ & $82.6^{\mathrm{abc}} \pm 0.1$ & $39.6^{\mathrm{f}} \pm 1.7$ \\
\hline Oct & $30.1^{\mathrm{ef}} \pm 1.3$ & $78.1^{\mathrm{e}} \pm 0.1$ & $68.2^{\mathrm{bc}} \pm 0.2$ \\
\hline Nov & $25.8^{\mathrm{fg}} \pm 0.5$ & $42.7^{\mathrm{b}} \pm 0.1$ & $73.8^{\mathrm{b}} \pm 5.4$ \\
\hline Dec & $21.5^{\mathrm{g}} \pm 1.6$ & $33.0^{\mathrm{i}} \pm 0.1$ & $46.1^{\mathrm{ef}} \pm 1.1$ \\
\hline Jan & $39.9^{\mathrm{d}} \pm 2.0$ & $78.2^{\mathrm{de}} \pm 1.2$ & $71.3^{\mathrm{b}} \pm 1.3$ \\
\hline Feb & $56.3^{\mathrm{b}} \pm 0.7$ & $81.6^{\mathrm{bcd}} \pm 0.1$ & $54.1^{\mathrm{de}} \pm 1.6$ \\
\hline Mar & $25.9^{\mathrm{fg}} \pm 1.3$ & $56.0^{\mathrm{g}} \pm 1.7$ & $75.6^{\mathrm{b}} \pm 2.1$ \\
\hline Apr & $46.8^{\mathrm{cd}} \pm 1.6$ & $80.5^{\mathrm{cde}} \pm 0.1$ & $36.2^{\mathrm{f}} \pm 0.6$ \\
\hline May & $27.2^{\mathrm{fg}} \pm 0.8$ & $70.3^{\mathrm{f}} \pm 0.3$ & $75.6^{\mathrm{b}} \pm 0.5$ \\
\hline Jun & $49.0^{\mathrm{bc}} \pm 2.6$ & $81.5^{\mathrm{bcd}} \pm 0.1$ & $97.8^{\mathrm{a}} \pm 0.4$
\end{tabular}

Mean \pm standard deviation $(n=3)$. Equal letters after the mean indicate that, at the $5 \%$ significance level, there is no difference between the means.

Phenolic compounds constitute a diverse group of secondary metabolites with important functions in plants, which have a wide variety of structures, from simple molecules to complex polymers [20], including flavonoids, phenolic acids, tannins, and lignans [21]. These compounds are synthesized in response to different situations, such as stress and environmental conditions [27], so that the phenolic composition of a plant is strongly influenced by the environment, as plants regulate the biosynthesis of their phytochemicals to optimize their survival [18]. As a result, variations in the composition of the plant are not 
constant throughout the year [17], as observed for the total phenolic content of $N$. variegata leaves collected in different months, mainly from December/2017 to June/2018.

Phenolic compounds have important biological activities, such as antioxidants, antiinflammatory, antimicrobial and anti-cancer. These compounds stimulate cellular defenses, prevent chronic-degenerative diseases and fight to age. As a result, plants rich in phenolic compounds have the great pharmacological potential [18]. As presented, even though there is variation in the total phenolic content of the extracts, the leaves of Neoglaziovia variegata are rich in phenolic compounds, therefore this plant has potential for pharmacological exploration.

As previously discussed, $N$. variegata leaves have secondary metabolites of different classes, many of which have already been attributed to antioxidant activity. The antioxidant activity of leaf extracts was evaluated in vitro using spectrophotometric assays, and the results are shown in Table 3. The percentage of inhibition of the $\mathrm{DPPH}^{\bullet}$ radical ranged from $33.0 \pm$ 0.1 to $86.1 \pm 0.2$, with the highest antioxidant potential obtained for the extract of the leaves collected in August/2017, while the lowest antioxidant capacity was observed in the extract of the leaves collected in December/2017. The percentage of inhibition of the ABTS $^{\cdot+}$ radical varied between $36.2 \pm 0.6$ and $97.8 \pm 0.4$, so that the extract of leaves collected in April/2018 showed the lowest antioxidant capacity and the extract of the leaves collected in June/2018 had the highest antioxidant potential. For most of the collection months, it was verified that $N$. variegata leaves showed percentages of inhibition of free radicals greater than $70 \%$, indicating that the leaves of $N$. variegata are rich in antioxidant compounds.

According to the Tukey test, for both methods, there was a statistically significant difference in the percentage of inhibition of radicals by extracts of leaves collected in different months, indicating that the antioxidant activity of $N$. variegata varied significantly throughout the year. As the phytochemical composition of the plant is affected by several factors (biotic and abiotic) and the composition directly influences the biological activities of the plant, samples collected at different times of the year may present significant differences in its composition and, consequently, in its biological activities [18], as the antioxidant activity.

As can be seen in Table 3, the extract with the highest TPC (July/2017) did not show the highest antioxidant activity, and for extracts, with the lowest TPC (May/2018, for example), high percentages of inhibition of free radicals were obtained. As highlighted earlier, Neoglaziovia variegata leaves have several secondary metabolites with antioxidant properties, not just phenolic compounds, which justifies this observation.

Another aspect that should be highlighted is that some extracts showed high antioxidant potential against the DPPH radical and low antioxidant activity against the ABTS radical, as in the leaves collected in September/2017, February/2018, and April/2018. The inverse was also observed for extracts of the leaves collected in November/2017 and March/2018, with high antioxidant activity against $\mathrm{ABTS}^{\circ+}$ and low antioxidant potential against $\mathrm{DPPH}$. Each method is based on a specific mechanism. The antioxidant compounds show different potentials against different radicals, so it is important to use different methods to assess a sample's antioxidant activity [27]. In addition, several plant phytochemicals exhibit antioxidant activity, and the antioxidant mechanism may include synergistic effects [21]. Therefore, the differences observed are justified since it was demonstrated that the leaves of Neoglaziovia variegata have different antioxidant compounds. 


\subsection{HPLC-DAD analyses.}

Applying HPLC-DAD analyses, the chromatograms shown in Figures 1 and 2 were obtained. In Figure 1, the chromatograms in the max plot mode $(260-360 \mathrm{~nm}$ ) of the extracts of $N$. variegata leaves collected for 12 consecutive months are compared. In Figure 2, there is a comparison of chromatograms of the extract of leaves collected in March/2018 at the different wavelengths analyzed, highlighting the peaks of the identified analytes, some of which are not visible due to the scale of the graph.

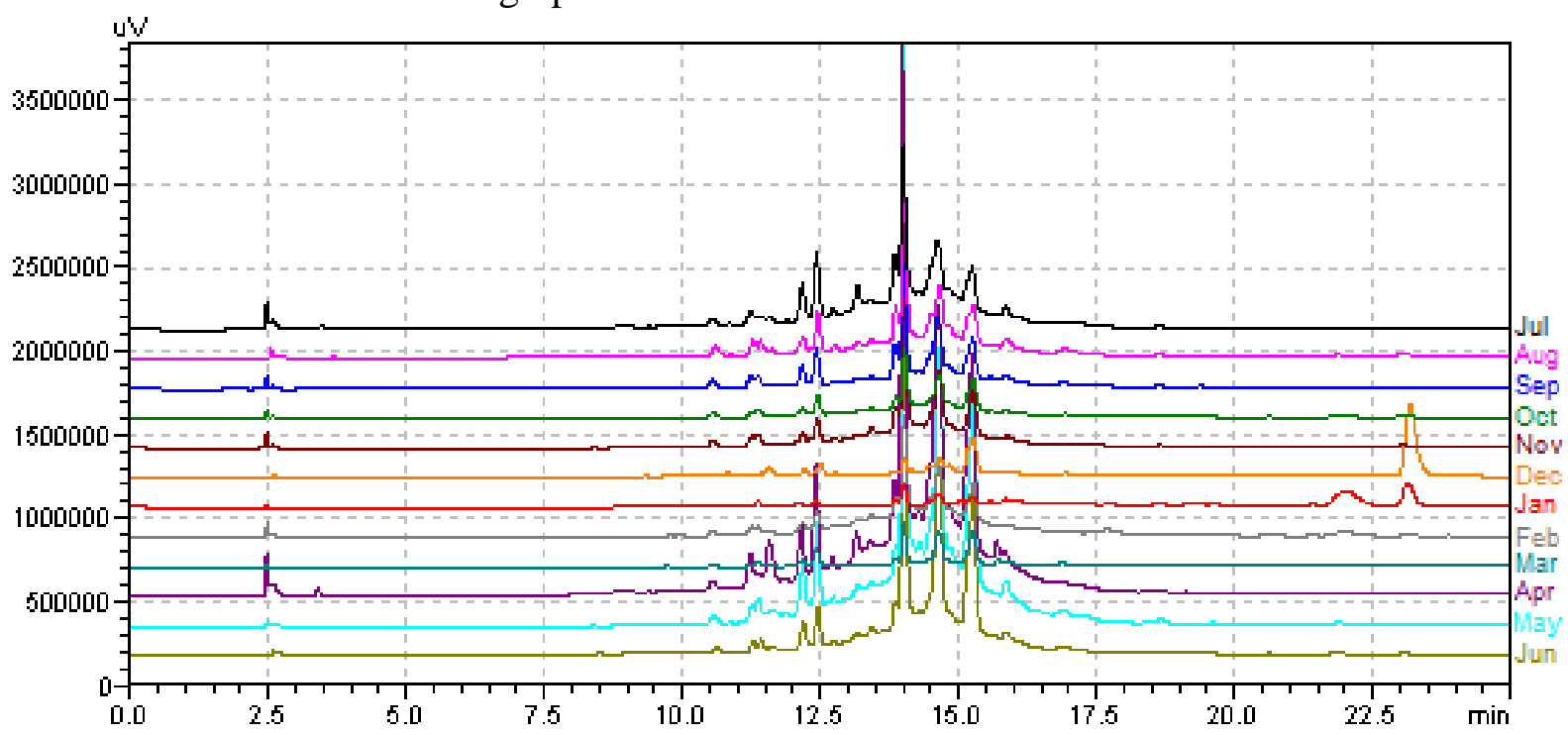

Figure 1. Comparison of chromatograms (max plot 260-360 nm) of the extracts of Neoglaziovia variegata leaves collected for 12 consecutive months.

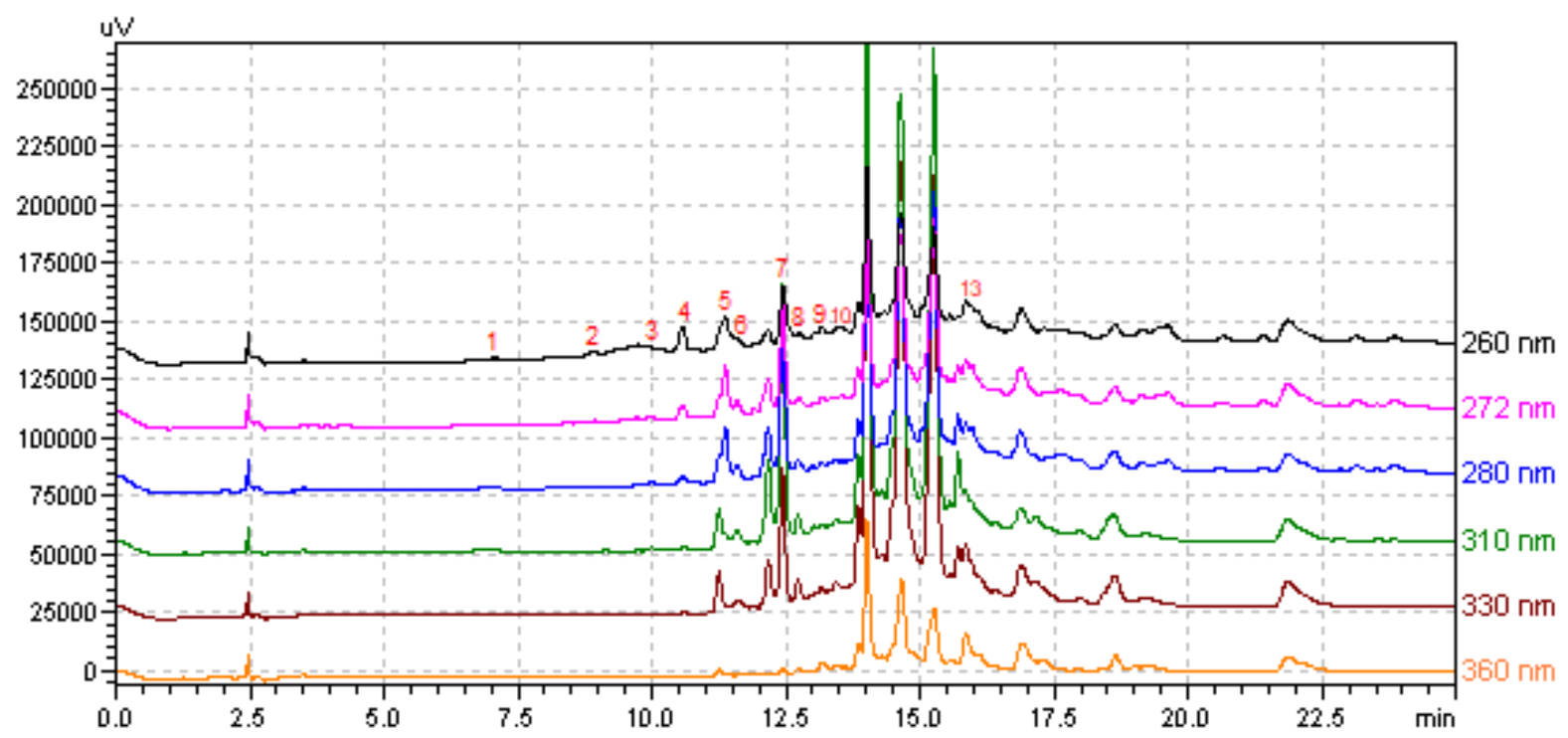

Figure 2. Comparison of chromatograms of the extract of leaves collected in March/2018 at the different wavelengths (260-360 nm), highlighting the analyte peaks (1: gallic acid; 2: protocatechuic acid; 3: catechin; 4: chlorogenic acid; 5: caffeic acid; 6: syringic acid; 7: p-coumaric acid; 8: ferulic acid; 9: rutin; 10: ellagic acid;

13: kaempferol).

It was possible to identify four flavonoids (catechin, rutin, quercetin, and kaempferol), quantified in the extracts of $N$. variegata leaves collected every month for a year, whose concentrations are presented in Table 4. Chrysin and naringenin were not identified in any of the extracts analyzed. Among the flavonoids identified, the highest concentrations were obtained for kaempferol. Comparing the months of collection, it is evident that the 
concentrations of these secondary metabolites varied over a year. Comparing the concentrations obtained, it can also be noted that the leaves collected in April/2018 showed higher concentrations of the four identified flavonoids.

Table 4. Flavonoid concentrations (mg/g) in extracts of Neoglaziovia variegata leaves collected in different seasons.

\begin{tabular}{l|c|c|c|c} 
Sample & Catechin & Rutin & Quercetin & Kaempferol \\
\hline Jul & $0.15 \pm 0.01$ & $1.24 \pm 0.02$ & $0.76 \pm 0.02$ & $2.01 \pm 0.04$ \\
\hline Aug & $0.43 \pm 0.02$ & $0.26 \pm 0.01$ & $0.35 \pm 0.01$ & $1.90 \pm 0.02$ \\
\hline Sep & $0.23 \pm 0.01$ & $0.17 \pm 0.01$ & $0.26 \pm 0.01$ & $1.02 \pm 0.01$ \\
\hline Oct & $0.13 \pm 0.01$ & $0.15 \pm 0.01$ & $0.15 \pm 0.01$ & $0.61 \pm 0.01$ \\
\hline Nov & $0.40 \pm 0.01$ & $0.18 \pm 0.01$ & $0.26 \pm 0.01$ & $0.78 \pm 0.01$ \\
\hline Dec & $0.37 \pm 0.01$ & $0.08 \pm 0.01$ & $0.18 \pm 0.01$ & $0.60 \pm 0.01$ \\
\hline Jan & $0.29 \pm 0.01$ & $0.09 \pm 0.01$ & $0.14 \pm 0.01$ & $0.98 \pm 0.02$ \\
\hline Feb & $0.23 \pm 0.01$ & $0.18 \pm 0.01$ & $0.31 \pm 0.02$ & $0.59 \pm 0.01$ \\
\hline Mar & $0.12 \pm 0.01$ & $0.08 \pm 0.01$ & $0.13 \pm 0.01$ & $0.47 \pm 0.01$ \\
\hline Apr & $0.54 \pm 0.02$ & $1.16 \pm 0.03$ & $1.30 \pm 0.03$ & $2.65 \pm 0.07$ \\
\hline May & $0.43 \pm 0.01$ & $0.59 \pm 0.02$ & $1.01 \pm 0.02$ & $3.57 \pm 0.05$ \\
\hline Jun & $0.17 \pm 0.01$ & $0.32 \pm 0.01$ & $0.31 \pm 0.01$ & $1.69 \pm 0.02$
\end{tabular}

Mean \pm standard deviation $(n=3)$.

The biosynthesis of phenolic compounds in the plant may take some time depending on the type of compound, such as flavonoids [18]. Therefore, the composition determined in a month can be a plant response to the stress and environmental conditions of the previous month or months. In Brazil, the month of April is autumn, but the previous month (March) marks the end of summer, the season in which the days are longer than the nights, causing the plant to be subjected to a higher incidence of ultraviolet radiation. Exposure to high levels of light may lead to increased defense mechanisms of the plant, altering biochemical processes, especially of phenolic compounds that are directly related to the protection and adaptability of the plant [17]. It is known that flavonoids have a role in protecting the plant against UV radiation [28]. Thus, the high concentration of flavonoids in the leaves collected in April/2018 may be due to the plant's defense mechanism in response to the excess of light suffered during the summer.

Eight phenolic acids were identified in all $N$. variegata leaf extracts, and their concentrations are shown in Table 5. For these phenolic compounds, variability in concentrations in leaves collected in different months was also verified. The presence of caffeic, protocatechuic, and p-coumaric acids in Neoglaziovia variegata leaves has already been reported [7].

Table 5. Concentration of trans-cinnamic and phenolic acids (mg/g) in extracts of Neoglaziovia variegata leaves collected in different seasons.

\begin{tabular}{|c|c|c|c|c|c|c|c|c|c|}
\hline Sample & TCA & FA & $\mathrm{CA}$ & CFA & CLA & PRA & GA & EA & SA \\
\hline Jul & $0.022 \pm 0.008$ & $0.19 \pm 0.01$ & $2.21 \pm 0.05$ & $0.66 \pm 0.01$ & $0.20 \pm 0.01$ & $0.08 \pm 0.01$ & $0.16 \pm 0.01$ & $2.83 \pm 0.03$ & $0.43 \pm 0.02$ \\
\hline Aug & $0.020 \pm 0.002$ & $0.30 \pm 0.01$ & $1.24 \pm 0.01$ & $0.71 \pm 0.01$ & $0.13 \pm 0.02$ & $0.06 \pm 0.01$ & $0.15 \pm 0.01$ & $1.93 \pm 0.02$ & $0.47 \pm 0.01$ \\
\hline Sep & $0.009 \pm 0.002$ & $0.13 \pm 0.01$ & $1.21 \pm 0.03$ & $0.59 \pm 0.02$ & $0.11 \pm 0.01$ & $0.04 \pm 0.01$ & $0.14 \pm 0.02$ & $1.90 \pm 0.03$ & $0.28 \pm 0.01$ \\
\hline Oct & n.d. & $0.12 \pm 0.01$ & $0.60 \pm 0.01$ & $0.25 \pm 0.01$ & $0.04 \pm 0.01$ & $0.03 \pm 0.01$ & $0.12 \pm 0.01$ & $0.71 \pm 0.01$ & $0.17 \pm 0.01$ \\
\hline Nov & n.d. & $0.16 \pm 0.01$ & $0.72 \pm 0.02$ & $0.49 \pm 0.01$ & $0.07 \pm 0.01$ & $0.04 \pm 0.01$ & $0.13 \pm 0.01$ & $1.30 \pm 0.02$ & $0.21 \pm 0.01$ \\
\hline Dec & $0.023 \pm 0.004$ & $0.15 \pm 0.02$ & $0.39 \pm 0.01$ & $0.19 \pm 0.01$ & $0.02 \pm 0.01$ & $0.03 \pm 0.01$ & $0.08 \pm 0.01$ & $0.26 \pm 0.01$ & $0.10 \pm 0.01$ \\
\hline Jan & $0.134 \pm 0.012$ & $0.20 \pm 0.01$ & $0.19 \pm 0.01$ & $0.08 \pm 0.01$ & $0.05 \pm 0.01$ & $0.05 \pm 0.01$ & $0.08 \pm 0.01$ & $0.36 \pm 0.01$ & $0.03 \pm 0.01$ \\
\hline Feb & n.d. & $0.10 \pm 0.01$ & $0.60 \pm 0.01$ & $0.39 \pm 0.01$ & $0.06 \pm 0.01$ & $0.04 \pm 0.01$ & $0.08 \pm 0.01$ & $1.11 \pm 0.01$ & $0.10 \pm 0.01$ \\
\hline Mar & $0.040 \pm 0.009$ & $0.08 \pm 0.01$ & $0.63 \pm 0.01$ & $0.16 \pm 0.01$ & $0.02 \pm 0.01$ & $0.02 \pm 0.01$ & $0.10 \pm 0.01$ & $0.39 \pm 0.01$ & $0.05 \pm 0.01$ \\
\hline Apr & n.d. & $0.39 \pm 0.02$ & $3.59 \pm 0.04$ & $1.62 \pm 0.02$ & $0.46 \pm 0.03$ & $0.16 \pm 0.02$ & $0.09 \pm 0.01$ & $3.31 \pm 0.03$ & $1.18 \pm 0.02$ \\
\hline May & $0.006 \pm 0.002$ & $0.25 \pm 0.01$ & $2.74 \pm 0.02$ & $0.82 \pm 0.04$ & $0.05 \pm 0.01$ & $0.23 \pm 0.01$ & $0.08 \pm 0.01$ & $1.70 \pm 0.06$ & $0.25 \pm 0.01$ \\
\hline Jun & $0.009 \pm 0.002$ & $0.08 \pm 0.01$ & $1.29 \pm 0.02$ & $0.54 \pm 0.01$ & $0.07 \pm 0.01$ & $0.03 \pm 0.01$ & $0.18 \pm 0.02$ & $1.37 \pm 0.02$ & $0.24 \pm 0.01$ \\
\hline
\end{tabular}

CFA: caffeic acid; CLA: chlorogenic acid; PRA: protocatechuic acid; GA: gallic acid; EA: ellagic acid; SA: syringic acid. 
Vanillic acid was not identified in any of the extracts analyzed, although its presence has been reported in the ethanolic extract of $N$. variegata leaves previously [7]. trans-Cinnamic acid was identified in most extracts, except in the leaves collected in October/2017, November/2017, February/2018, and April/2018. As previously discussed, the composition of the plant may undergo qualitative and quantitative variations as a result of an adaptive process of survival in response to different external factors. As a consequence, some metabolites may be biosynthesized in greater or lesser amounts or even be absent in the plant at a given time [18].

Among the identified phenolic acids, higher concentrations were obtained for $p$ coumaric and ellagic acids. In the leaves collected in April/2018, the highest concentration was obtained for 6 of the 8 phenolic acids determined. As previously mentioned, this may be the result of the plant's response to the conditions experienced during the summer, which is the season that ends before that month. In the summer, the temperatures are higher, the days are longer, and in the Northeast of Brazil, the rains are beginning, which have a short duration and strong intensity [29]. Phenolic compounds act in the protection and adaptability of the plant [17] and, as secondary metabolites, their biosynthesis by the plant is influenced by light intensity, water availability, and temperature [19].

The results of HPLC-DAD analyses corroborate with the results of TPC, having been verified the variation of the phenolic composition of the leaves of Neoglaziovia variegata during one year. It is noteworthy that the biosynthesis and the accumulation of phenolic compounds in the plant can be influenced by several endogenous and exogenous factors. The physiological condition is the main intrinsic factor, and several external factors can strongly influence the production of phenolic compounds in the plant. These exogenous factors reflect biotic and abiotic environmental stimuli, such as seasonality, temperature, availability of water and light, atmospheric and soil composition, interaction with pathogens and parasites, and feeding of insects or herbivorous animals [30].

Even though there is variation in the concentrations of phenolic acids and flavonoids in Neoglaziovia variegata leaves during the year, it is noteworthy that these identified analytes have several beneficial health properties and biological activities with possible applications in medicine and the pharmaceutical, food, and cosmetic industries, indicating the potential for scientific exploration of this species of plant.

Catechins have the most important antioxidant, chemopreventive activities [26], and anti-inflammatory [27]. Rutin shows anti-cancer [28], antioxidant and anti-inflammatory activities, hepatoprotective effect, inhibits platelet aggregation, and reduces the level of cholesterol in the blood [29]. Quercetin possesses antiviral, anti-cancer, anti-inflammatory, and antioxidant activities and has been used to treat allergies, cardiovascular diseases, and arthritis [30]. Kaempferol has antioxidant, anti-tumor, anti- antimicrobial, anti-inflammatory, cardioprotective, and neuroprotective activities [31,32].

Ferulic acid displays antioxidant, antimicrobial [33], anti-cancer, anti-inflammatory, and antidiabetic activities [34]. $p$-Coumaric acid possesses antineoplastic, antimicrobial, antiinflammatory, and antioxidant activities [35] and hepatoprotective and nephroprotective effects [36]. Caffeic acid has anticarcinogenic, antioxidant, anti-inflammatory, antimicrobial activities [37], anti-angiogenic, and anti-atherosclerotic [38]. Chlorogenic acid presents anticarcinogenic, anti-neurodegenerative, antidiabetic, anti-hypertensive, antilipidemic, antiinflammatory, and antioxidant activities [39]. Protocatechuic acid has antioxidant, antiinflammatory, anti-hyperglycemic, anti-hypertensive activities, cardiovascular-protective [40], 
and neuroprotective properties [41]. Gallic acid shows anti-cancer, anti-inflammatory, antioxidant, antimicrobial [42], antidiabetic, and anti-ulcerogenic [43]. Ellagic acid displays antioxidant, anti-inflammatory, antimicrobial, antiviral, antimutagenic, anticarcinogenic, antidiabetic cardioprotective activities [44-46]. Syringic acid presents antimicrobial, antioxidant, anti-inflammatory, and antiendotoxic activities [47] and neuroprotective effects [48].

\subsection{Principal Components Analysis (PCA).}

The principal component analysis is based on the correlation among multiple variables and the reduction of the dimensions of the original data set using a smaller number of new variables, called principal components (PCs), which preserve the original characteristics of the data set, as reliably as if the original variables were used [43]. Projection graphics for cases and variables are obtained with PCA, so that it is possible to identify which analytes have the greatest influence on sample separation. Thus, the data interpretation is simplified, and it is possible to extract as much information from the data that conventional analysis is not able to demonstrate [15].

PCA was applied to the phenolic composition data (concentration of phenolic acids and flavonoids) of the extracts of Neoglaziovia variegata leaves collected during 12 consecutive months to evaluate the influence of seasonality on the phenolic profile of this species. The nonrotated matrix was used for the analysis of components. Of the 11 principal components extracted, only the PCs with eigenvalues $\geq 1$ and that explain at least $10 \%$ of the total variance of the data were selected. Therefore, the projection graphs of cases and variables were plotted in the PC1 $\times$ PC2 plane (Figure 3), which explains almost $80 \%$ of the data variability, satisfactorily for the extraction and interpretation of information. PC1 explains most of the data variation $(65.39 \%)$, while PC2 explains $14.20 \%$ of the total variance.

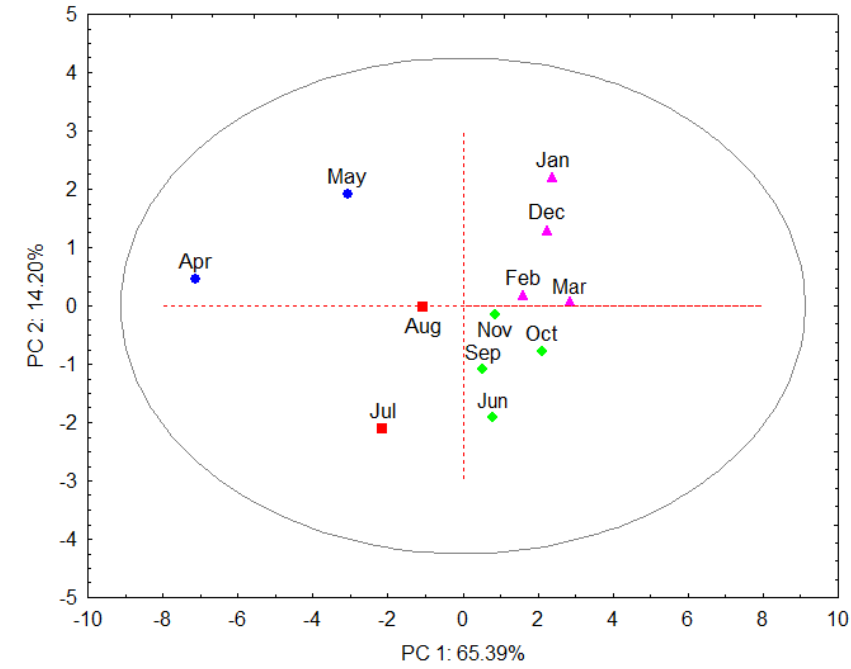

(a)

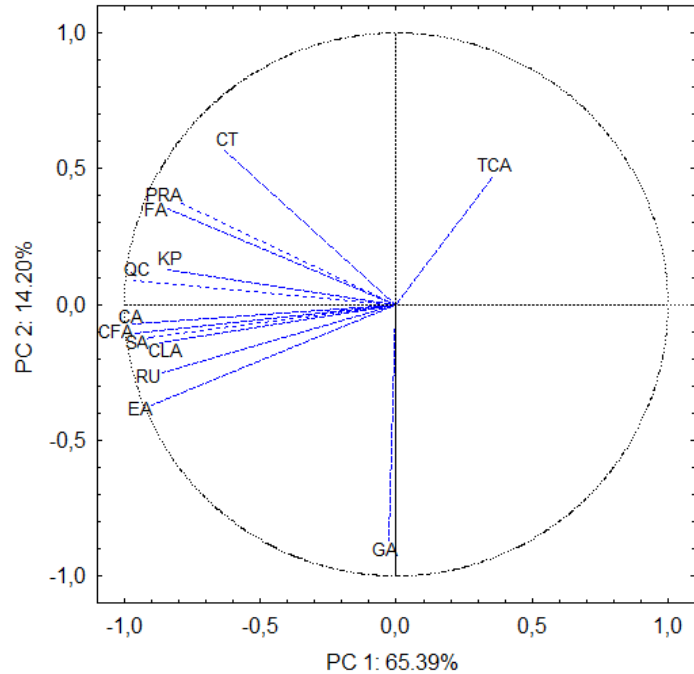

(b)

Figure 3. (a) Projection of cases on the plane PC1× PC2; (b) Projection of variables in the plane PC1 $\times$ PC2.

The projection graph of the cases (Figure 3a) shows the formation of 4 groups according to the quadrant, and the projection graph of the variables (Figure $3 \mathrm{~b}$ ) indicates the analytes responsible for the grouping. A group is formed by the samples collected in December/2017, January/2018, February/2018, and March/2018, positively correlated with both PC1 and PC2, with grouping mainly influenced by trans-cinnamic acid. In December, the summer season 
begins, which extends through the months of January, February, and March, and is characterized by longer and hotter days, with rapid changes in daily weather conditions that lead to rapid and intense rains. In the Northeast region of Brazil, summer marks the beginning of the rainy season, with a peak in February [29].

The group of samples collected in April and May (2018) has a negative correlation with PC1 and a positive correlation with PC2, so that the grouping occurred mainly due to catechin, quercetin, kaempferol, ferulic and protocatechuic acids. The months of April and May are part of the autumn season, which in the Northeast region of Brazil is marked by the rainiest period and the most homogeneous temperatures [29].

A group is composed of the samples collected in July and August (2017), which has a negative correlation with both PC1 and PC2, and their grouping had a greater influence on the variables rutin, $p$-coumaric, caffeic, syringic, chlorogenic, ellagic, and gallic acids. July and August are winter months, a season in which temperatures are lower, and the relative humidity is high [29].

The samples collected in June/2018, September/2017, October/2017, and November/2017, form a group, positively correlated with PC1 and negatively correlated with PC2. The month of June is marked by the transition of seasons, with the beginning of winter, and in September, there is a transition from winter to spring. The September, October, and November trimester is characterized by the dry season in Northeast Brazil. There is little variation in temperature throughout the year in the Northeast region of Brazil [29]. Two variables had a greater influence on the inclusion of the June sample in this group and its separation from the other autumn and winter samples: gallic acid (in greater concentration than in the months of April and May) and trans-cinnamic acid (in a lower concentration than in the months of July and August), similar in the September, October and November samples.

Evaluating the distribution of the samples according to the principal components, it is verified that PC1 has a negative correlation to samples collected in April, May, July and August, which had the highest concentrations for most analytes, while samples collected in the other months, with lowest concentrations for most phenolic compounds identified, are positively correlated with PC1. More importantly, in relation PC2, the division of the samples was strongly influenced by the occurrence of rain. PC2 is positively correlated with the months (December, January to May) of the rainy period (summer and autumn seasons), while it has a negative correlation with the months (June to November) of the dry season (winter and spring).

In view of the observations of the formation of groups of samples according to the seasons, the influence of seasonality on the phenolic profile of $N$. variegata leaves is evident. Even with variations in the concentrations of phenolic acids and flavonoids during the year, plotting a confidence ellipse (marked in gray in Figure 3a) was verified that the elliptical region involving all samples with $95 \%$ confidence, indicating that the phenolic composition of the samples of leaves is similar so that the identified analytes can be assumed as phytochemicals biomarkers of the species Neoglaziovia variegata.

\section{Conclusions}

The extracts of Neoglaziovia variegata leaves have a good antioxidant capacity, high concentration of phenolic compounds, and a wide variety of phytochemicals. The plant's antioxidant activity and phytochemical composition varied during the year, as discussed with the Tukey test, and there was a great seasonal influence, as PCA evidenced. With PCA it could also be shown that the identified phenolic compounds can be used as biomarkers of the species. 
Identifying several phytochemicals with known and important biological activities highlights the scientific potential to be explored of the species Neoglaziovia variegata.

\section{Funding}

This research was funded by Fundação de Amparo à Ciência e Tecnologia do Estado de Pernambuco (FACEPE) (Process IBPG-1313-4.03/16) and Conselho Nacional de Desenvolvimento Científico e Tecnológico (CNPq).

\section{Acknowledgments}

The authors declare no acknowledgments.

\section{Conflicts of Interest}

The authors declare no conflict of interest.

\section{References}

1. Espejo-Serna, A.; López-Ferrari, A.R.; Ramírez-Morillo, I. Bromeliaceae. Flora del Bajío y de Regiones Adyacentes 2009, 165, 145.

2. Zanella, C.M.; Janke, A.; Palma-Silva, C.; Kaltchuk-Santos, E.; Pinheiro, F.G.; Paggi, G.M.; Soares, L.E.S.; Goetze, M.; Büttow, M.V.; Bered, F. Genetics, evolution and conservation of Bromeliaceae. Genet. Mol. Biol. 2012, 35, 1020-1026, https://doi.org/10.1590/S1415-47572012000600017.

3. Almeida, J.R.M.; Almeida, A.L.F.S.; Carvalho, L.H. Mechanical, morphological, and structural characteristics of caroa (Neoglaziovia variegata) fibres. Polym. Polym. Compos. 2008, 16, 589-595, https://doi.org/10.1177/096739110801600902.

4. Paula, C.C.; Guarconi, E.A.E. Neoglaziovia variegata: a fiber-producing Brazilian Bromeliad. Journal of the Bromeliad Society 2007, 57, 119-120.

5. Machado, F.D.F.; Silva, F.V.; Fernandes, H.B.; Freitas, F.F.B.P.; Arcanjo, D.D.R.; Lima, J.T.; Almeida, J.R.G.S.; Oliveira, F.A.; Oliveira, R.C.M. Gastroprotective effect of an ethanolic extract from Neoglaziovia variegata (Arruda) Mez (Bromeliaceae) in rats and mice. Z. Naturforsch. C 2013, 68, 97-107, https://doi.org/10.1515/znc-2013-3-404.

6. Lima-Saraiva, S.R.G.; Saraiva, H.C.C.; Silva, J.C.; Lima, J.T.; Siqueira-Filho, J.A.; Damasceno, P.K.F.; Branco, C.R.C.; Branco, A.; Amorim, E.L.C.; Almeida, J.R.G.S. Antinociceptive effect of the ethanolic extract of Neoglaziovia variegata (Bromeliaceae) in mice. J. Med. Plant. Res. 2012a, 6, 5330-5336, https://doi.org/10.5897/JMPR12.122.

7. Oliveira-Júnior, R.G.; Souza, G.R.; Guimarães, A. L.; Oliveira, A.P.; Araújo, C. S.; Silva, J.C.; Pacheco, A.G.M.; Lima-Saraiva, S.R.G.; Rolim, L.A.; Rolim-Neto, P.J.; Castro, R.N.; Almeida, J.R.G.S. Photoprotective, antibacterial activity and determination of phenolic compounds of Neoglaziovia variegata (Bromeliaceae) by high performance liquid chromatography-diode array detector (HPLC-DAD) analysis. Afr. J. Pharm. Pharmacol. 2015, 9, 576-584, https://doi.org/10.5897/AJPP2015.4315.

8. Oliveira-Júnior, R.G.; Araújo, C. S.; Souza, G.R.; Guimarães, A.L.; Oliveira, A.P.; Lima-Saraiva, S.R.G.; Morais, A.C.S.; Santos, J.S.R.; Almeida, J.R.G.S. In vitro antioxidant and photoprotective activities of dried extracts from Neoglaziovia variegata (Bromeliaceae). J. Appl. Pharm. Sci. 2013, 3, 122-127, https://doi.org/10.7324/JAPS.2013.30124.

9. Lima-Saraiva, S.R.G.; Guimarães, A.L.; Oliveira, A.P.; Saraiva, H.C.C.; Oliveira-Junior, R.G.; Barros, V.R.P.; Menezes, V.G.; Oliveira, R.A.; Silva, F.S.; Lima, R.S.; Matos, M.H.T.; Amorim, E.L.C.; Almeida, J.R.G.S. Antioxidant activity and acute toxicity of Neoglaziovia variegata (Bromeliaceae). Afr. J. Biotechnol. 2012b, 11, 13998-14006, https://doi.org/10.5897/AJB12.1913.

10. Juvik, O.J.; Holmelid, B.; Francis, G.W.; Andersen, H.L.; Oliveira, A.P.; Oliveira-Junior, R.G.; Almeida, J.R.G.S.; Fossen, T. Non-polar natural products from Bromelia laciniosa, Neoglaziovia variegata and Encholirium spectabile (Bromeliaceae). Molecules 2017, 22, 1-13, https://doi.org/10.3390/molecules22091478.

11. Ibrahim, A.H.H.; Herfindal, L.; Rathe, B.; Andersen, H.L.; Almeida, J.R.G.; Fossen, T. A novel polyoxygenated flavone glucosid from aerial parts of the Brazilian plant Neogaziovia variegata (Bromeliaceae). Heliyon 2019, 5, e01369, https://doi.org/10.1016/j.heliyon.2019.e01369. 
12. Wagner, H.; Bladt, S. Plant Drug Analysis: A Thin Layer Chromatography Atlas, 2nd ed.; Springer: Berlin, Germany, 1996, https://doi.org/10.1007/978-3-642-00574-9.

13. Peixoto-Sobrinho, T.J.S.; Castro, V.T.N.A.; Saraiva, A.M.; Almeida, D.M.; Tavares, E.A.; Pisciottano, M.N.C.; Amorim, E.L.C. Phytochemical screening and antibacterial activity of four Cnidoscolus species (Euphorbiaceae) against standard strains and clinical isolates. J. Med. Plants Res. 2012, 6, 3742-3748, https://doi.org/10.5897/JMPR11.1533.

14. Magalhães, B.E.A.; Santos, W.N.L. Phenolic content and antioxidant capacity of infusions herbs: Optimization of phenolic extraction and HPLC-DAD method. An. Acad. Bras. Ciênc. 2020, 92, e20190646, https://doi.org/10.1590/0001-3765202020190646.

15. Magalhães, B.E.A.; Santana, D.A.; Silva, I.M.J; Minho, L.A.C.; Gomes, M.A.; Almeida, J.R.G.S; Santos, W.N.L. Determination of phenolic composition of oil seed whole flours by HPLC-DAD with evaluation using chemometric analyses. Microchem. J. 2020, 155, 104683, https://doi.org/10.1016/j.microc.2020.104683.

16. Kabera, J.N.; Edmond Semana, E.; Mussa A.R.; He, X. Plant Secondary Metabolites: Biosynthesis, Classification, Function and Pharmacological Properties. J. Pharm. Pharmacol. 2014, 2, 377-392.

17. Ribeiro, D.A.; Macêdo, D.G.; Boligon, A.A.; Menezes, I.R.A.; Souza, M.M.A.; Costa, J.G.M. Influence of seasonality on the phenolic composition of Secondatia floribunda A.DC (Apocynaceae) during its phenological cycle. Acta Physiol. Plant 2019, 41, 185, https://doi.org/10.1007/s11738-019-2975-X.

18. Ribeiro, D.A.; Camilo, C.J.; Nonato, C.F.A.; Rodrigues, F.F.G.; Menezes, I.R.A.; Ribeiro-Filho, J.; Xiao, J.; Souza, M.M.A.; Costa, J.G.M. Influence of seasonal variation on phenolic content and in vitro antioxidant activity of Secondatia floribunda A. DC. (Apocynaceae). Food Chem. 2020, 315, 126277, https://doi.org/10.1016/j.foodchem.2020.126277.

19. Gobbo-Neto, L.; Lopes, N.P. Medicinal plants: factors of influence on the content of secondary metabolites. Quím Nova 2007, 30, 374-381, https://doi.org/10.1590/S0100-40422007000200026.

20. Negri, M.; Salci, T.P.; Shinobu-Mesquita, C.S.; Capoci, I. R. G.; Svidzinski, T.I.E.; Kioshima, E.S. Early state research on antifungal natural products. Molecules 2014, 19, 2925-2956, https://doi.org/10.3390/molecules19032925.

21. Shahidi, F.; Ambigaipalan, P. Phenolics and polyphenolics in foods, beverages and spices: Antioxidant activity and health effects - A review. J. Funct. Foods 2015, 18, 820-897, https://doi.org/10.1016/j.jff.2015.06.018.

22. Ahmed, E.; Arshad, M.; Khan, M.Z.; Amjad, M.S.; Sadaf, H.M.; Riaz, I.; Sabir, S.; Ahmad, N.; Sabaoon. Secondary metabolites and their multidimensional prospective in plant life. J. Pharmacogn. Phytochem. 2017, 6, 205-214.

23. Eyong, K.O.; Kuete, V.; Efferth, T. Quinones and Benzophenones from the Medicinal Plants of Africa. In Medicinal Plant Research in Africa; Kuete, V.; Elsevier: Oxford, United Kingdom, 2013; 351-391, https://doi.org/10.1016/B978-0-12-405927-6.00010-2.

24. El-Najjar, N.; Gali-Muhtasib, H.; Ketola, R.A.; Vuorela, P.; Urtti, A.; Vuorela, H. The chemical and biological activities of quinones: overview and implications in analytical detection. Phytochem. Rev. 2011, 10, 353-370, https://doi.org/10.1007/s11101-011-9209-1.

25. Kashani, H.H.; Hoseini, E.S.; Nikzad, H.; Aarabi, M.H. Pharmacological properties of medicinal herbs by focus on secondary metabolites. Life Sci. J. 2012, 9, 509-520.

26. Latos-Brozio, M.; Masek, A. Natural polymeric compound based on high thermal stability catechin from green tea. Biomolecules 2020, 10, 1191, https://doi.org/10.3390/biom10081191.

27. Musial, C.; Kuban-Jankowska, A.; Gorska-Ponikowska, M. Beneficial Properties of Green Tea Catechins. Int. J. Mol. Sci. 2020, 21, 1744, https://doi.org/10.3390/ijms21051744.

28. Farha, A. K.; Gan, R.; Li, H.; Wu, D.; Atanasov, A. G.; Gul, K.; Zhang, J.; Yang, Q.; Corke, H. The anticancer potential of the dietary polyphenol rutin: Current status, challenges, and perspectives. Crit. Rev. Food Sci. Nutr. 2020, 1-28, https://doi.org/10.1080/10408398.2020.1829541.

29. Kalinová, J.P.; Vrchotová, N.; Tříska, J. Contribution to the study of rutin stability in the achenes of Tartary buckwheat (Fagopyrum tataricum). Food Chem 2018, 258, 314-320, https://doi.org/10.1016/j.foodchem.2018.03.090.

30. Batiha, G.E.; Ikram, A.M.B.M.; Mulla, Z.S.; El-Hack, M.E.A.; Taha, A.E.; Algammal, A.M.; Elewa, Y.H.A. The Pharmacological Activity, Biochemical Properties, and Pharmacokinetics of the Major Natural Polyphenolic Flavonoid: Quercetin. Foods 2020, 9, 374, https://doi.org/10.3390/foods9030374.

31. Imran, M.; Salehi, B.; Sharifi-Rad, J.; Gondal, T.A.; Saeed, F.; Imran, A.; Shahbaz, M.; Fokou, P.V.T.; Arshad, M.U.; Khan, H.; Guerreiro, S.G.; Martins, N.; Estevinho, L.M. Kaempferol: A Key Emphasis to Its Anticancer Potential. Molecules 2019, 24, 2277, https://doi.org/10.3390/molecules24122277.

32. Kim, J. K.; Park, S. U. Recent studies on kaempferol and its biological and pharmacological activities. EXCLI J. 2020, 19, 627, http://dx.doi.org/10.17179/excli2020-2162.

33. Berton, S. B. R.; Cabral, M. R. P.; Jesus, G. A. M.; Sarragiotto, M. H.; Pilau, E. J.; Martins, A. F.; Bonafé, E. G.; Matsushit M.. Ultra-high-performance liquid chromatography supports a new reaction mechanism 
between free radicals and ferulic acid with antimicrobial and antioxidant activities. Ind. Crops Prod. 2020, 154, 112701, https://doi.org/10.1016/j.indcrop.2020.112701.

34. Zduńska, K.; Dana, A.; Kolodziejczak, A.; Rotsztejn, H. Antioxidant Properties of Ferulic Acid and Its Possible Application. Skin Pharmacol. Physiol. 2018, 31, 332-336, https://doi.org/10.1159/000491755.

35. Ferreira, P.S.; Victorelli, F.D.; Fonseca-Santos, B.; Chorilli, M. A Review of Analytical Methods for pCoumaric Acid in Plant-Based Products, Beverages, and Biological Matrices. Crit. Rev. Anal. Chem. 2019, 49, 21-31, https://doi.org/10.1080/10408347.2018.1459173.

36. Mohamadi Yarijani, Z.; Najafi, H.; Madani, S.H. Protective Effect of P-Coumaric Acid against CisplatinInduced Nephrotoxicity and Hepatotoxicity in Rats. Journal of Mazandaran University of Medical Sciences 2020, 30, 1-13.

37. Yilmaz, S. Effects of dietary caffeic acid supplement on antioxidant, immunological and liver gene expression responses, and resistance of Nile tilapia, Oreochromis niloticus to Aeromonas veronii. Fish Shellfish Immunol. 2019, 86, 384-392, https://doi.org/10.1016/j.fsi.2018.11.068.

38. Silva, H.; Lopes, N. M. F. Cardiovascular effects of caffeic acid and its derivatives: a comprehensive review. Front. Physiol. 2020, 11, https://doi.org/10.3389/fphys.2020.595516.

39. Limwachiranon, J.; Huang, H.; Li, L.; Lin, X.; Zou, L.; Liu, J.; Zou, Y.; Aalim, H.; Duan, Z.; Luo, Z. Enhancing stability and bioaccessibility of chlorogenic acid using complexation with amylopectin: A comprehensive evaluation of complex formation, properties, and characteristics. Food Chem 2020, 311, 125879, https://doi.org/10.1016/j.foodchem.2019.125879.

40. Masodsai, K.; Lin, Y.; Chaunchaiyakul, R.; Su, C.; Lee, S.; Yang, A. Twelve-Week Protocatechuic Acid Administration Improves Insulin-Induced and Insulin-Like Growth Factor-1-Induced Vasorelaxation and Antioxidant Activities in Aging Spontaneously Hypertensive Rats. Nutrients 2019, 11, 699, https://doi.org/10.3390/nu11030699.

41. Li, Z.; Liu, Y.; Wang, F.; Gao, Z.; Elhefny, M.A.; Habotta, O.A.; Abdel Moneim, A.E.; Kassab, R.B. Neuroprotective effects of protocatechuic acid on sodium arsenate induced toxicity in mice: Role of oxidative stress, inflammation, and apoptosis. Chem.-Biol. Interact. 2021, 337, 109392, https://doi.org/10.1016/j.cbi.2021.109392.

42. Zhu, L.; Gu, P.; Shen, H. Gallic acid improved inflammation via NF-кB pathway in TNBS-induced ulcerative colitis. Int. Immunopharmacol. 2019, 67, 129-137, https://www.doi.org/10.1016/j.intimp.2018.11.049.

43. Zahrani, N. A. A.; El-Shishtawy, R. M.; Asiri, A. M. Recent developments of gallic acid derivatives and their hybrids in medicinal chemistry: A review. Eur. J. Med. Chem. 2020, 112609, https://doi.org/10.1016/j.ejmech.2020.112609.

44. Ceci, C.; Graziani, G.; Faraoni, I.; Cacciotti I. Strategies to improve ellagic acid bioavailability: from natural or semisynthetic derivatives to nanotechnological approaches based on innovative carriers. Nanotechnology 2020, 31, 382001, https://doi.org/10.1088/1361-6528/ab912c.

45. Rahimi, V.B.; Ghadiri, M.; Ramezani, M.; Askari, V.R. Antiinflammatory and anti-cancer activities of pomegranate and its constituent, ellagic acid: Evidence from cellular, animal, and clinical studies. Phytother. Res. 2020, 34, 685-720, https://doi.org/10.1002/ptr.6565.

46. Alfei, S.; Turrini, F.; Catena, S.; Zunin, P.; Grilli, M.; Pittaluga, A. M.; Boggia, R. Ellagic acid a multi-target bioactive compound for drug discovery in CNS? A narrative review. Eur. J. Med. Chem. 2019, 183, 111724, https://doi.org/10.1016/j.ejmech.2019.111724.

47. Srinivasulu, C.; Ramgopal, M.; Ramanjaneyulu, G.; Anuradha, C.M.; Suresh Kumar, C. Syringic acid (SA) - A Review of Its Occurrence, Biosynthesis, Pharmacological and Industrial Importance. Biomed. Pharmacother. 2018, 108, 547-557, https://doi.org/10.1016/j.biopha.2018.09.069.

48. Zhao, Y.; Dang, M.; Zhang, W.; Lei, Y.; Ramesh, T.; Veeraraghavan, V. P.; Hou, X. Neuroprotective effects of Syringic acid against aluminium chloride induced oxidative stress mediated neuroinflammation in rat model of Alzheimer's disease. J. Funct. Foods 2020, 71, 104009, https://doi.org/10.1016/j.jff.2020.104009. 